Thorax 1987;42:409-416

Original articles

\title{
Congenital bronchopulmonary vascular malformations: clinical application of a simple anatomical approach in 25 cases
}

\author{
B S CLEMENTS, J O WARNER, E A SHINEBOURNE
}

From the Department of Paediatrics, Brompton Hospital, London

ABSTRACT Congenital malformations of the bronchopulmonary airway and related arterial blood supply are a complex group of lesions in which abnormalities of venous drainage and lung parenchyma may coexist. Twenty five cases have been analysed, by a method whereby each anatomical component is separately considered. All 25 patients had abnormalities of the tracheobronchial tree, with no connection to the abnormal segment in nine cases. The aberrant arterial blood supply was single in 16 cases and multiple in nine cases, one patient from the latter group having a mixed pulmonary and systemic arterial supply to a part of the abnormal segment. Seventeen patients had anomalous venous drainage. In nine of these the vein or veins (they were multiple in four cases) drained the major part or the whole of the lung, whereas the aberrant arterial supply was limited to the right lower zone-that is, mismatched anomalous venous drainage. Abnormalities of lung parenchyma included changes within the lesion (for example, cysts, foregut inclusions) and associated abnormalities of surrounding lung (for example, hypoplasia, abnormal lobation). This information, together with the clinical features and haemodynamic data, was found to be essential for decisions on appropriate management. Patients presenting in infancy with haemodynamic disturbance continue to present major management problems (50\% mortality), particularly if there are associated congenital heart defects. The role of aberrant systemic artery occlusion or ligation as a first stage procedure is well established in patients with haemodynamic abnormalities. There may be a place for this procedure in selected patients who have no haemodynamic disturbance at presentation.

Congenital malformations of the lung are an ill defined group of conditions. To the paediatric chest physician abnormalities such as lung cysts, lobar emphysema, and cystadenomatoid malformations present as isolated conditions. To the paediatric cardiologist areas of abnormal lung with an anomalous systemic blood supply may present predominantly because of haemodynamic disturbance. In many instances, however, the clinical and morphological features in these two groups of patients show considerable overlap, differing only in their arterial blood supply. In both groups of patients there may be asso-

Address for reprint requests: Dr JO Warner, Department of Paediatrics, Brompton Hospital, London SW3 6HP.

Accepted 16 February 1987 ciated abnormalities of venous drainage (for example, scimitar syndrome) and lung parenchyma (for example, hypoplastic lung). These similarities support the view that the lesions form a spectrum of abnormal lung development in which any one or all of the different components may be affected. These components are the tracheobronchial airway, the arterial supply, the venous drainage, and the lung parenchyma. This has led us to adopt an approach whereby all these component features are considered in each case. In this paper we discuss the group of patients with abnormal lung development who are unified in that they have an associated aberrant systemic arterial blood supply to the abnormal segment. There is at present no generally accepted nomenclature or classification for this group of anomalies, although some authors have recommended that the lesions 
should be included in the sequestration spectrum. ${ }^{1-4}$ The inadequacies of the current terminology are discussed in an accompanying paper (p 401), and an alternative nomenclature and classification for all congenital lung malformations, including those with normal vasculature, is proposed.

\section{Patients}

At the Brompton Hospital and the Hospital for Sick Children, London, we have reviewed 25 cases with bronchopulmonary-vascular malformations in the five years 1981-85. The age at diagnosis ranged from five days to 22 years. Haemodynamic abnormality was the major factor responsible for presentation in infancy ( 15 cases). Of these patients, the lesion was located in the right lung in 14 patients and the left lung in one. Respiratory symptoms were predominant in patients presenting later (eight cases). Two children were symptom free at diagnosis; one had a lesion discovered coincidentally at thoracotomy, and the other was noted to have a heart murmur and dextrocardia on routine examination.

In all patients the abnormal anatomical component features were delineated as fully as possible. The influence of the various combinations of these abnormal components on clinical presentation and management would require a comprehensive table detailing this information with results of investigations in all 25 patients, which would be beyond the scope of this article. Instead we have chosen to analyse the prevalence of each of the component features (table 1), and to discuss each component separately, emphasising the wide variation encountered in these lesions.

\section{Abnormal anatomical components}

TRACHEOBRONCHIAL CONNECTION

All our patients had abnormalities of tracheobronchial airway connection. The range of abnormal communication extended from absent connection with a blind ending bronchus (agenesis) or an atretich membrane to apparently normal patency, with a gra年 dation of abnormality in between. In over $60 \%$ of out patients (17 cases) the lesion had some form of com는. munication with surrounding normal lung. In some (䎹 cases) this communication was fairly rudimentary? but in others (13 cases) it was reasonably well estabs lished with ventilated lung distal to it. The most coms mon finding at examination of resected or necropsy specimens from this latter group was hypoplastiē development of the tracheobronchial tree and abnors mal branching patterns, although in addition some had histological evidence of bronchial wall abnormaif ities and chronic infection. Seven patients were referred with the diagnosis of sequestration of th posterior basal segment of the left lower lobe (the commonest site for this type of lesion). The chest radiograph in all seven showed dense shadowing i $\overrightarrow{2}$ this region. Preoperative clinical assessment sugf gested absence of airway communication to the abnormal segment, as would traditionally $\vec{b} \oplus$ expected. Macroscopic and histological examination of the resected specimens from three of these patients however, showed clearly communicating but ectatis bronchi, with distorted parenchyma and evidence of chronic infection. One of these specimens containe two small non-communicating cysts within the pareng chyma of the abnormal segment. Possibly thes lesions, and some of the group described before this represent transitional stages in these abnormalities, in which chronic infection and cystic degeneration lead in time, to obliteration of bronchial connection and

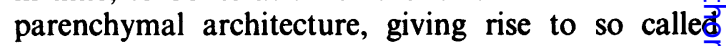
"classical sequestration"- that is, a "disconnecte bronchopulmonary mass with a systemic arteriat supply." 5

SYSTEMIC ARTERIAL SUPPLY

The aberrant systemic arterial supply to the abnorma segment was found to originate as a single trunk in 16 cases and multiple trunks in nine cases, one patierf from the latter group having a mixed systemic and

Table 1 Analysis of anatomical components in 25 cases of bronchopulmonary vascular malformation

\begin{tabular}{|c|c|c|c|c|c|c|c|}
\hline \multicolumn{2}{|c|}{ Tracheobronchial connection } & \multicolumn{2}{|c|}{ Systemic artery supply } & \multicolumn{2}{|c|}{ Venous drainage } & \multirow{2}{*}{$\begin{array}{l}\begin{array}{l}\text { Lung } \\
\text { parenchymal } \\
\text { abnormalities }\end{array} \\
\begin{array}{c}\text { Associated } \\
\text { hypoplasia }\end{array} \\
\begin{array}{c}\text { Abnormal } \\
\text { lobation }\end{array}\end{array}$} & \\
\hline Absent & 8 & Single & 16 & Normal & 8 & & \\
\hline Patent & 17 & Multiple & $9+$ & $\begin{array}{l}\text { Anomalous } \\
\text { Matched } \\
\text { Mismatched } \\
\text { Unknown }\end{array}$ & $\begin{array}{c}17 \ddagger \\
6 \\
9 \\
2\end{array}$ & $\begin{array}{l}\text { Extrapulmonary } \\
\text { lesions } \\
\text { Cystic changes }\end{array}$ & 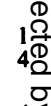 \\
\hline
\end{tabular}

* More than one of these may occur in the same patient.

$\dagger$ Includes one patient with mixed pulmonary and systemic artery supply. $\ddagger$ Four patients had more than one draining vein. 
pulmonary artery supply to a part of the abnormal segment. Figures 1 and 2 show how failure to delineate these features accurately may lead to management complications in a particular patient. In the first patient (fig 1) two anomalous arteries were seen to arise from the abdominal aorta with multiple branches piercing the diaphragm to supply the lower zone of the right lung. After thoracotomy and ligation of these vessels the child continued to have haemodyanamic problems. Repeat cardiac catheterisation (fig 2) showed the more proximal of the two trunks still to be patent and, in addition, a third tortuous vessel was now seen to arise from the thoracic aorta and to be supplying the same area. This vessel was not seen on the first angiogram as it lay behind the contrast filled left ventricle in the anteroposterior view. In another patient a pulmonary artery injection showed a branch descending from the hypoplastic right pulmonary artery to supply the medial right midzone posteriorly. A subsequent aortic injection revealed a branch from the aberrant systemic artery supplying the same area both on the anteroposterior and lateral views, thus confirming a mixed pulmonary and systemic arterial supply to this part of the abnormal lung segment. This phenomenon has been previously recognised. ${ }^{6}$

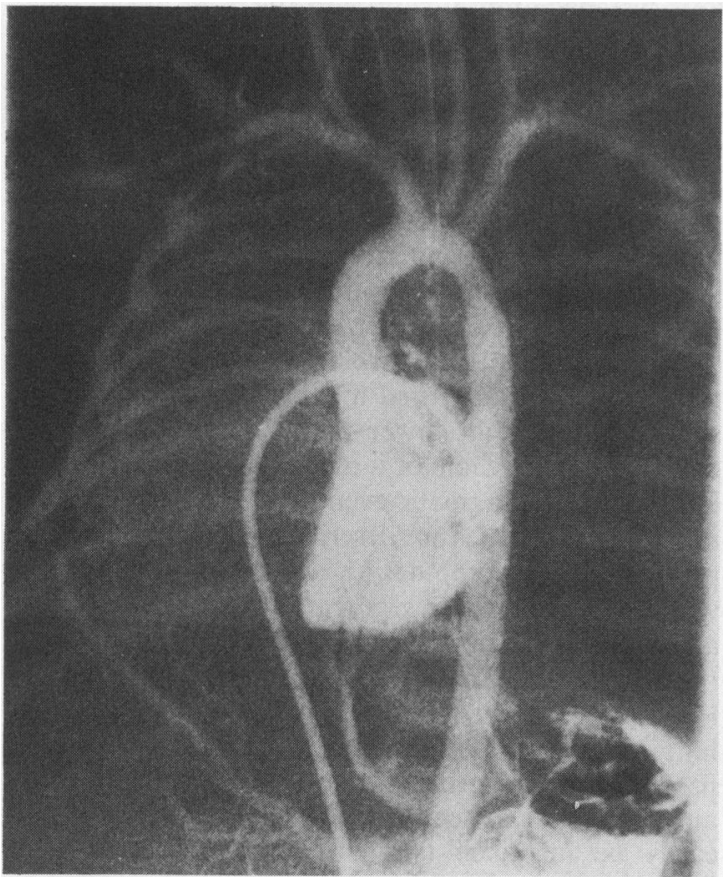

Fig 1 Injection of contrast into the left ventricle of a 2 week old infant with normal intracardiac anatomy. Two anomalous vessels are seen arising from the abdominal aorta with multiple branches piercing the diaphragm to supply the lower zone of the right lung.

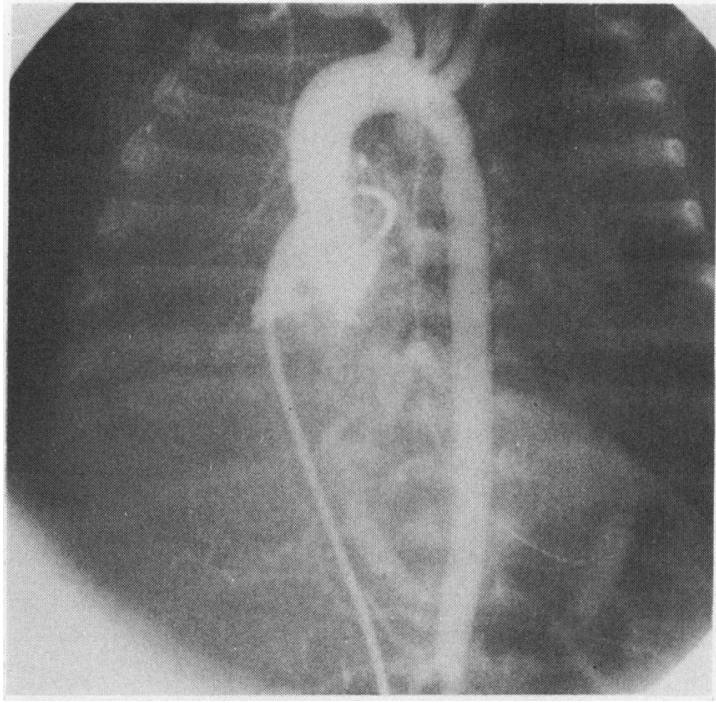

Fig 2 Aortic contrast injection one week after ligation of the two anomalous vessels seen in figure 1. Two further vessels are now seen arising from the aorta and supplying the same abnormal segment.

\section{VENOUS DRAINAGE}

Seventeen patients $(68 \%)$ had anomalous venous drainage, but in only one of these was the lesion extrapulmonary, as traditionally expected. The other 16 had intrapulmonary lesions, in which according to earlier ideas normal venous drainage is customary. ${ }^{5}$ In nine of these the anomalous vein or veins drained not only the abnormal segment but the major part or whole of that lung (figs 3 and 4), conforming to the scimitar arrangement. ${ }^{7-10}$ We emphasise the importance of this aspect with the following two cases. In the first patient injection of contrast into the aberrant systemic artery (fig 3 ) outlines the vein draining the right lower zone and the direction of the vein suggests that it drains at least part of the upper zone as well. Should this patient have a right lower lobectomy, ligation of this trunk would result in infarction of the rest of the right lung and almost inevitably in death. In another patient two venous channels are outlined (fig 4) that drain most of the right lung. Ligation of one of these trunks occurred inadvertently in one patient, with the disastrous consequences we have described. There was more than one draining vein in four patients.

\section{ABNORMALITIES OF LUNG PARENCHYMA}

Here we describe the site of the abnormal segment, abnormalities within the abnormal segment itself (for example, cysts, adenomas, ectopic foregut inclusions), and associated abnormalities of surrounding lung (for example, hypoplasia, abnormal lobation). 


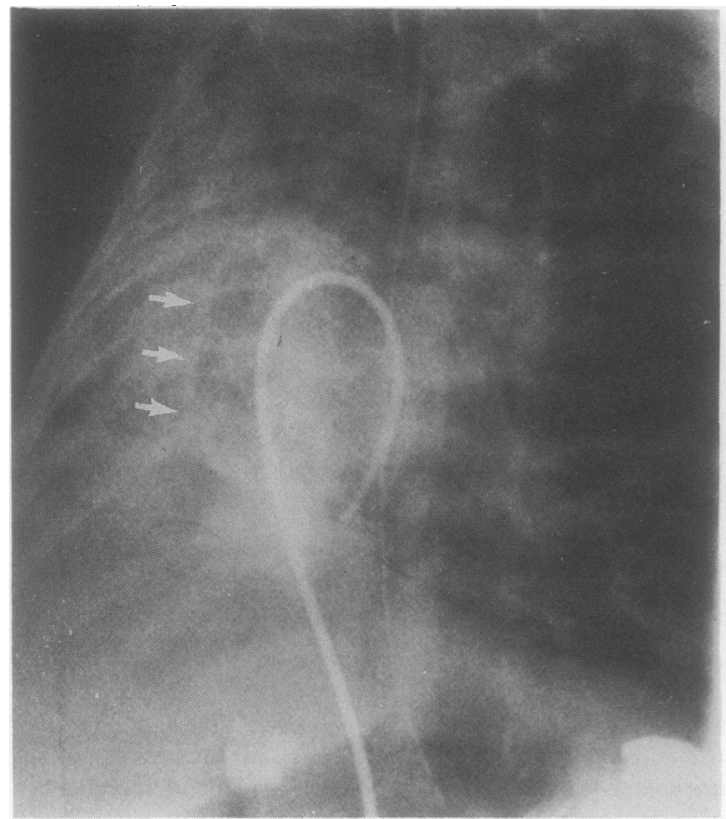

Fig 3 The venous phase after injection of contrast into the aberrant systemic artery of a 3 week old infant. A single anomalous vein (arrowed) is seen draining the right lower zone (supplied by the aberrant systemic artery) to the inferior vena cava, but the direction of the vein suggests that it drains at least part of the upper zone as well (which is supplied by a hypoplastic right pulmonary artery). Thus there is mismatched anomalous venous drainage of the right lung.

In 24 cases the site of the lesion was intrapulmonary (enclosed within the pleural layer surrounding the lung). These abnormalities were found in the right lower zone in 16 cases, the right upper zone in one case, and the left lower zone in seven cases. Only one patient in our series had an extrapulmonary lesion (ectopic lung tissue lying outside the pleura surrounding the rest of the lung). This lesion was discovered coincidentally in the right upper zone posteriorly in a patient undergoing thoracotomy for removal of a bronchogenic cyst. Associated pulmonary hypoplasia was recognised in 13 patients by radiographic evidence of reduced lung volume, a small thoracic cage on that side, and usually mediastinal shift. The hypoplasia always occurred on the right side. Abnormal lobation was found in $\mathbf{1 0}$ patients but may well have been present in others where it was not delineated, particularly in those patients with associated lung hypoplasia and mismatched anomalous venous drainage. Abnormal lobar patterns generally took the form of a unilobar or bilobar right lung, but in three patients we found an arrangement which, to our knowledge, has not been previously described. One underwent thoracotomy for ligation of the anoma-

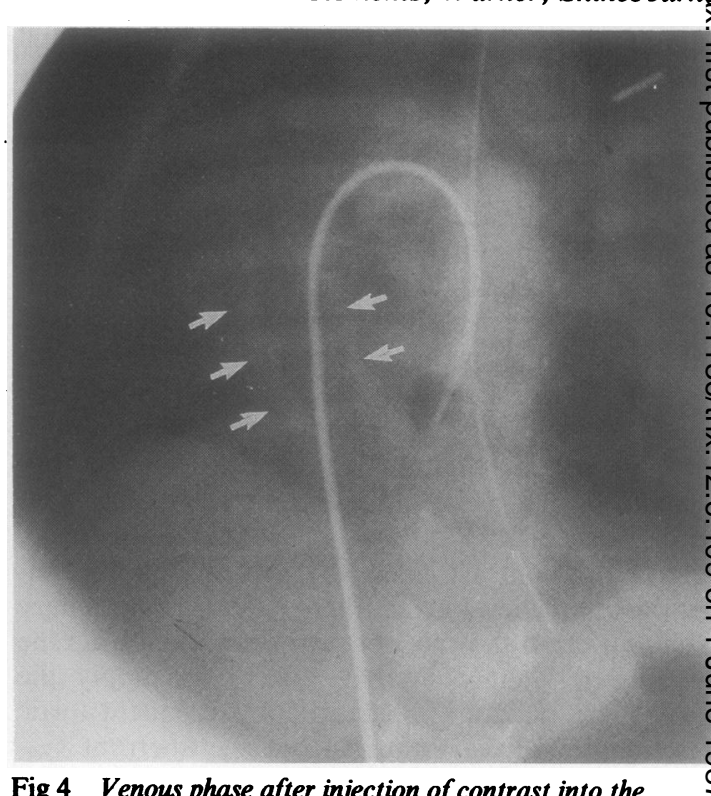

Fig 4 Venous phase after injection of contrast into the aberrant systemic arterial system with two venous trunks outlined, draining most of the right lung to the inferior vena cava in this 6 week old infant.

lous systemic arterial supply to the right lower zone⿻ The right lung was noted to be bilobar with the uppee zone hypoplastic and supplied by a hypoplastic righ? pulmonary artery. From the inferior medial aspect of the right upper zone a segment of lung extendes across the midline into the left hemithorax. The pul monary artery angiogram in this case (fig 5) shows hypoplastic right pulmonary artery with tw branches traversing the midline to supply the crossover segment. In all three patients the finding of the crossover segment was associated with a hypoplastie right lung with abnormal lobation, aberrant arteria supply to the right lower zone, anomalous venoug drainage of the whole or a major portion of the right lung, and diaphragmatic eventration or hernia on the same side. The cases are described in detail in anothe paper. ${ }^{10}$ This combination of abnormalities, but without the crossover segment, is well recognised, $1 \mathrm{~N}$ and was noted in another patient from our series. If the anteroposterior view at angiography the anomao lous systemic supply to the lower zone of the right lung was seen to be superimposed on the liver, whic $\overline{5}$ projects into the eventration. This gives the appear? ance of a vascularised liver tumour, for which it could easily be mistaken (similar to the appearance i fig 1). ${ }^{11}$

\section{Associated congenital lesions}

Associated diaphragmatic, ${ }^{5}$ cardiovascular, ${ }^{11}$ gastrog 


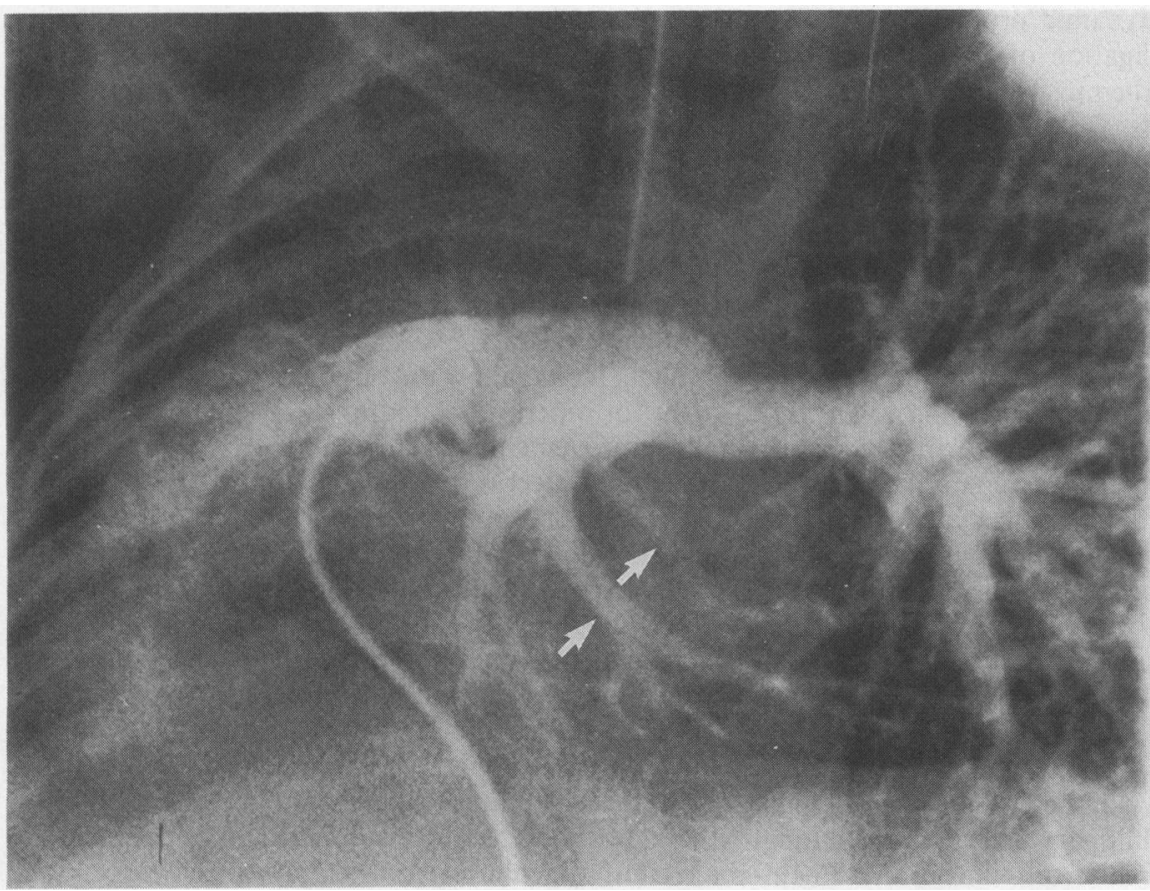

Fig 5 Right sided

diaphragmatic eventration, severe right lung hypoplasia, and dextrocardia in a 2 week old infant, with a catheter tip sited in the main pulmonary artery. Injected contrast outlines two branches of the hypoplastic right pulmonary artery (arrowed) crossing the midline to supply a segment in the left mid zone posteriorly. At thoracotomy this was found to be a crossover segment of right lung extending into the left hemithorax.

intestinal, ${ }^{2}$ and other respiratory tract anomalies ${ }^{1}$ were noted in 14 of our patients. These must all be considered in the planning of management-in at least four patients they were a major factor contributing to death. We have found the combination of severe right lung hypoplasia and associated congenital heart disease a poor prognostic feature in bronchopulmonary-vascular malformations. Of the intracardiac defects, atrial septal defect was the commonest (eight cases), in keeping with most other reports. ${ }^{12}$ One patient with an atrial septal defect also had a ventricular septal defect and patent ductus arteriosus. The two remaining patients both had ventricular septal defects, one in association with coarctation of the aorta. There were three diaphragmatic eventrations and two diaphragmatic hernias, all on the right side and associated with right lung hypoplasia. One patient had a gastric duplication cyst connected by a fibrous band through the diaphragm to an intrapulmonary abnormal segment containing ectopic pancreatic tissue. This patient also had anal anomalies and has been described elsewhere. ${ }^{13}$ An exomphalos was seen in one patient with a left sided intrapulmonary lesion.

\section{Discussion}

Congenital malformations of the lung with abnormal vasculature are an ill defined group of conditions. They have a wide range of anatomical variation, which may lead to problems in diagnosis and management. To avoid confusion, we have adopted a simple anatomical approach that delineates separately the four major component features of these anomalies-namely, the tracheobronchial airway, arterial supply, venous drainage, and lung parenchymal abnormalities. In this paper we concentrate on those lesions with an aberrant systemic arterial supply, emphasising that abnormalities of venous drainage and lung parenchyma may coexist and should be sought.

All parenchymal lung lesions should be suspected as having abnormal vasculature. The unpredictability of the vascular connections demands that both the arterial supply and the venous drainage are outlined in each case. ${ }^{38}$ Thus cardiac catheterisation with angiography remains the essential investigation in bronchopulmonary-vascular anomalies. ${ }^{41314}$ At catheterisation a pulmonary artery injection of contrast is mandatory for defining the extent of the normal pulmonary artery supply and associated hypoplasia and showing whether a "mixed" arterial supply to the abnormal segment is present. Aortic injection is used to identify an aberrant systemic arterial supply. Patients presenting in infancy usually 
have additional haemodynamic problems. ${ }^{15-19} \mathrm{We}$ agree with others that ligation of the aberrant systemic arteries is usually the most successful first stage procedure in such infants. ${ }^{16-20-22}$ Balloon occlusion or embolisation of the feeding vessels is an attractive alternative to surgical ligation. ${ }^{20}$ We have successfully embolised these vessels in one infant presenting with heart failure; he is now well and thriving, with normal pulmonary artery pressure at repeat catheterisation one year later. Reversal of pulmonary hypertension and clinical improvement after occlusion of the aberrant systemic artery is well recognised, ${ }^{1620-22}$ and may tide these patients over until they are old enough for definitive repair. The options would then include continued conservative management, correction of anomalous venous return, ${ }^{22-24}$ lobectomy, and pneumonectomy. The optimal age for definitive surgery would be influenced by the patient's symptoms and the skill and confidence of the surgeon. Reimplantation of the anomalous vein is best deferred until at least 3-5 years of age and preferably later, if symptoms allow. Prognosis for good restoration of function is best when there is a well developed right lung and right pulmonary artery and the lung has been relatively free from infection. Pneumonectomy under one year of age is almost always fatal and in this age group all efforts should be directed at conservative management.

Prophylactic occlusion of the aberrant systemic supply in patients with no evidence of haemodynamic disturbance deserves some consideration. Several reports have shown that even in symptom free patients there is a considerable shunt through this anomalous circuit. ${ }^{25-28}$ After removal of the abnormal segment there is a measured improvement in cardiovascular condition. ${ }^{25-28}$ In addition to the haemodynamic load, there is evidence that systemic pressures and flow predispose the abnormal segment to infection and contribute to the development of cystic degeneration. ${ }^{29-34}$ Our infant who had his aberrant systemic artery occluded by embolisation remains free from chest symptoms, while another one whose aberrant artery was not occluded developed a troublesome cough and tachypnoea within three months. One case report involving an older child describes complete resolution of symptoms, signs, and chest radiograph changes in an abnormal lobe after ligation of the systemic supply. ${ }^{34}$ This lobe had had all of the features of classical sequestration with apparently no bronchial connection seen from bronchography. Many lesions with intermediate bronchial and parenchymal changes, similar to those in some of our cases, have been described. ${ }^{30-34}$ In at least some patients these lesions may represent transitional stages in the progression of abnormality, where the lesion found at diagnosis in older children or adults may bear little resemblance to the abnormality present at birth. All of this points to a role foros occlusion of the aberrant systemic artery in infantso who do not have parenchymal changes ato presentation, in the hope that some of these changes may be prevented and later surgery avoided. $A_{\triangle} \mathbb{\Phi}$ double bonus may also be achieved in patients whow already have parenchymal damage, in whom surgical resection would be the usual consideration Embolisation of the systemic arterial supply to this $\vec{\omega}$ segment would allow the option of expectant manage-o ment for a period related to the degree of symptom $\vec{x}$ atic improvement. ${ }^{34}$ If surgical resection was then stills considered necessary, the risk of vascular compli $-\stackrel{N}{\sigma}$ cations at operation-a major source of morbiditys and mortality - would be greatly reduced. Infarctiono of the lung or segment after occlusion of the systemic artery supply has not been reported and it is just possible that in some of these patients the pulmonarye artery supply to this area would improve with time. $\vec{\Phi}$

Pulmonary infarction after ligation of the anoma $\vec{\bullet}$ lous venous trunk is, however, recognised in patientso with the scimitar arrangement. ${ }^{9}$ In this condition there is characteristically a mismatch between theo aberrant systemic arterial supply to the right lowes zone and the anomalous venous drainage of the whole or major part of the right lung. ${ }^{89}$ This makes lobectomy or segmentectomy of the right lower zone difficult. The importance of outlining the venous drainage in this anomaly has been emphasised by recent reports, ${ }^{39}$ and by two of our cases (figs and 4).

With abnormalities of the tracheobronchial airway and lung parenchyma, clinical history, physical exam ination, and plain chest radiography are usually sufficient for deciding how these components influence management. In most cases bronchoscop and bronchography provide no useful additiona information ${ }^{28}$; but they may be necessary if an alternative diagnosis, such as foreign body or bronchi ectasis, is suggested.

Grossly cystic and bronchiectatic areas may have to be removed surgically, but not before the vascuor lature has been outlined. In patients selected for conservative management with occlusion of th\& anomalous systemic artery alone, serial radioisotope scans may be useful in assessing progress.

OPERATIVE MORTALITY

In a survey of 350 cases from 27 published reports we divided the patients into those with haemodynamig problems and those without. The high mortalit $(85 \%)$ in the group with clinical evidence of cardias overload confirmed that these patients present majof management problems. The mortality in our patient within this group $(50 \%$-table 2$)$ may indicate $a$ 
Table 2 Management and outcome in the 25 cases

\begin{tabular}{|c|c|c|c|c|}
\hline & & \multirow[b]{2}{*}{ Management } & \multicolumn{2}{|c|}{ Outcome } \\
\hline & & & Alive & Dead \\
\hline Abnormal haemodynamics at presentation & 17 & $\begin{array}{l}\text { Vascular occlusion (5) } \\
\text { Resection } \\
\text { segmentectomy (0) } \\
\text { lobectomy (7) } \\
\text { pneumonectomy (2) } \\
\text { Conservative (3) } \\
\text { Total (17) }\end{array}$ & $\begin{array}{r}1 \\
\frac{6}{6} \\
10\end{array}$ & $\begin{array}{l}4^{*} \\
\frac{1}{2} \\
\frac{1}{7}\end{array}$ \\
\hline Normal haemodynamics at presentation & 8 & $\begin{array}{l}\text { Resection } \\
\text { segmentectomy (1) } \\
\text { lobectomy (6) } \\
\text { No treatment (1) } \\
\text { Total (8) }\end{array}$ & $\frac{1}{6}$ & $\frac{-}{1+}$ \\
\hline
\end{tabular}

*All four patients had severe right lung hypoplasia and intracardiac anomalies contributing to their death.

$\dagger$ Died of septicaemia before appropriate treatment could be administered.

improving trend, which we are tempted to attribute to the approach outlined in this paper. In patients presenting without clinical evidence of haemodynamic side effects, we have had no surgical deaths (table 2). On the other hand, considerable mortality in this group has been reported by others, ${ }^{35} 36$ almost entirely as a result of unexpected vascular complications encountered during surgery performed without accurate preoperative assessment. This emphasises the fact that even clinically benign lung anomalies may have complicated vasculature that can make surgery hazardous.

\section{SUMMAR Y}

Congenital malformations of the tracheobronchial tree and related arterial supply are a complex group of lesions where associated abnormalities of venous drainage and lung parenchyma may coexist. Using our experience of 25 cases, we have developed an approach whereby all these anatomical component features are considered in each case. This information, together with the clinical findings and haemodynamic data, is essential for decisions on appropriate management. The wide variation encountered in these conditions is emphasised by analysis of the prevalence of the component features. The role of aberrant systemic artery occlusion or ligation as a first stage procedure is well established in patients with haemodynamic abnormalities. In addition, there may be a role for this procedure in selected patients who have no haemodynamic disturbance at presentation for the reasons stated. The approach outlined in this paper may lead to improved understanding and management of these complicated congenital malformations.

We would like to express our thanks to Mr J Stark, consultant cardiothoracic surgeon, Hospital for Sick Children, Great Ormond Street, London, for his helpful comments and for allowing us the use of his patients for this report.

\section{References}

1 Sade RM, Clouse M, Ellis FH. The spectrum of pulmonary sequestration. Ann Thorac Surg 1974; 18:644-55.

2 Derksen OS. Scimitar syndrome and pulmonary sequestration. Radiol Clin 1977;46:81-93.

3 Thilenius OG, Ruschhaupt DG, Replogle RL, Bharati S, Herman T, Arcilla RA. Spectrum of pulmonary sequestration: association with anomalous pulmonary venous drainage in infants. Pediat Cardiol 1983; 4:97-103.

4 Flye MW, Conley M, Silver D. Spectrum of pulmonary sequestration. Ann Thorac Surg 1976;22:478-82.

5 Pryce DM. Lower accessory pulmonary artery with intralobar sequestration of lung: a report of seven cases. J Pathol 1946;58:457-67.

6 Lau YL, Radhi JM, Blesovsky A, Hunter AS. A case of middle lobe pulmonary sequestration. Thorax 1986; 41:810-1.

7 Neill CA, Ferencz C, Sabiston DC, Sheldon H. The familial occurrence of hypoplastic right lung with systemic arterial supply and venous drainage "scimitar syndrome”. Bull Johns Hopkins Hosp 1960;107:1-21.

8 Jue KL, Amplatz K, Adams P, Anderson RC. Anomalies of great vessels associated with lung hypoplasia. Am J Dis Child 1966;111:35-44.

9 Alivizatos P, Cheatle T, de Leval M, Stark J. Pulmonary sequestration complicated by anomalies of pulmonary venous return. J Pediat Surg 1985;20:76-9.

10 Clements BS, Warner JO. The crossover lung segment: a congenital malformation associated with a variant of scimitar syndrome. Thorax 1987;42:417-9.

11 Macpherson RI, Whytehead L. Pseudosequestration. J Can Ass Radiol 1977;28:17-25. 
12 Mathey J, Galey JJ, Logeais Y, et al. Anomalous venous return into inferior vena cava and associated bronchovascular anomalies (the scimitar syndrome). Thorax 1968;23:398-407.

13 Corrin B, Danel C, Allaway A, Warner JO, Lenney W. Intralobar pulmonary sequestration of ectopic pancreatic tissue with gastropancreatic duplication. Thorax 1985;40:630-8.

14 Newton Turk L, Lindskog GE. The importance of angiographic diagnosis in intralobar pulmonary sequestration. J Thorac Cardiovasc Surg 1961; 41:299-304.

15 Moritz VE, Keiler A, Schlick W. Intralobare Lungensequester. Zbl Chirurgie 1982;107:1022-7.

16 Levine MM, Nudel DB, Gootman N, Wolpowitz A, Wisoff $\mathrm{G}$. Pulmonary sequestration causing congestive heart failure in infancy: a report of two cases and review of the literature. Ann Thorac Surg 1981;34:581-5.

17 Haworth SG, Sauer U, Buhlmeyer K. Pulmonary hypertension in scimitar syndrome in infancy. Br Heart $J$ 1983;50:182-9.

18 Mortensson W, Lundstrom NR. Broncho-pulmonary vascular malformation syndrome causing left heart failure during infancy. Acta Radiol 1971;11:449-59.

19 Ransom JM, Norton JB, Williams GD. Pulmonary sequestration presenting as congestive heart failure. $J$ Thorac Cardiovasc Surg 1978;76:378-80.

20 Dickinson DF, Galloway RW, Massey R, Sankey R, Arnold R. Scimitar syndrome in infancy. Br Heart $J$ 1982;47:468-72.

21 Litwin SB, Plauth WH, Nadas AS. Anomalous systemic arterial supply to the lung causing pulmonary-artery hypertension. N Engl J Med 1970;283:1098-9.

22 Woody JN, Graham TP, Bradford WD, Sabiston DC, Canent RV. Hypoplastic right lung with systemic blood supply and anomalous pulmonary venous drainage: reversal of pulmonary hypertension with surgical management in infancy. Am Heart $J$ 1972;83:82-8.

23 Yonehiro EG, Hallman GL, Cooley DA. Anomalous pulmonary venous return from a hypoplastic right lung to the inferior vena cava (scimitar syndrome): report of successful correction and review of surgical treatment. Cardiovascular Research Centre Bulletin1966;4:106-17.

24 Honey M. Anomalous pulmonary venous drainage of $\frac{\bar{\sigma}}{\bar{\omega}}$

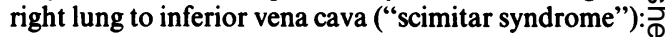
clinical spectrum in older patients and role of surgery. $\varrho$ Q J Med 1977;46:463-83.

25 Masuda H, Ogata T, Tanaka S, Kikuchi K, Yoshizu H, Takagi K. Blood flow in the abnormal artery of an. intralobar sequestration [English abstract]. Nippon $\overrightarrow{-}$ Kyobu Geka 1984;32:2119-22.

26 Solit RW, Frainow W, Wallace S, Cohn HE. The effect of intralobar pulmonary sequestration on cardiac out- $x$ put. J Thorac Cardiovasc Surg 1965;49:844-52.

27 Kergin FG. Congenital cystic disease of the lung associated with anomalous arteries. $J$ Thorac Surg $\underset{\odot}{\stackrel{0}{0}}$ 1952;23:55-60.

28 O'Mara CS, Baker RR, Jeyasingham K. Pulmonary윽 sequestration. Surg Gyn Obst 1978;147:609-15.

29 Abbey Smith R. A theory of the origin of intralobar sequestration of lung. Thorax 1956;11:10-24.

30 Heitzman ER. The lung: radio-pathologic correlations. 2nd ed. St Louis: CV Mosby, 1984:17-38.

31 Flisak ME, Chandrasekar AJ, Marsan RE, Ali MM. v Systemic arterialisation of lung without sequestration. Am J Radiol 1982;138:751-3.

32 Takahashi M, Ohno M, Mihara K, Matsuura K, Sumiyoshi A. Intralobar pulmonary sequestration. ำ Radiology 1975;114:543-9.

33 Groot H. Lung sequestration. Radiol Clin 1975;45: 49-56.

34 Makinen EO, Merikanto J, Rikalainen H, Satokari K. 3 Intralobar sequestration occurring without alteration? of pulmonary parenchyma. Pediat Radiol 1981,0 10:237-40.

35 Briccoli A, Mastrorilli M, Spangaro M, et al. La seques trazione polmonare. Minerva Chirurge 1982; 37:523-40.

36 Telander RL, Lennox C, Sieber W. Sequestration of the lung in children. Mayo Clin Proc 1976;51:578-84. 